\title{
Antioxidant Activity, Total Phenolic and Flavonoid Content of Berberis aristata DC. and Berberis thomsoniana C.K. Schneid. from Sagarmatha National Park, Nepal
}

\author{
Lok Ranjan Bhatt*, Bina Wagle, Minu Adhikari, Santoshi Bhusal, Anjana Giri, Shandesh Bhattarai
}

\section{Lok Ranjan Bhatt*, Bina Wagle, Minu Adhikari, Santoshi Bhusal, Anjana Giri, Shandesh Bhattarai}

Biological Resources unit, Faculty of Science, Nepal Academy of Science and Technology, Khumaltar, Lalitpur, NEPAL.

Correspondence

Dr. Lok Ranjan Bhatt

Senior Scientific Officer, Biological Resources Unit, Faculty of Science, Nepal Academy of Science and Technology, Khumaltar, Lalitpur, NEPAL.

Phone no : +977 15547714

E-mail: lokranjan.bhatta@nast.gov.np, lokranjan2000@yahoo.com

\section{History}

- Submission Date: 22-06-2018

- Review completed: 07-08-2018;

- Accepted Date: 28-09-2018

DOI : 10.5530/pj.2018.6s.29

Article Available online http://www.phcogj.com/v10/i6s

\section{Copyright}

(C) 2018 Phcog.Net. This is an openaccess article distributed under the terms of the Creative Commons Attribution 4.0 International license.

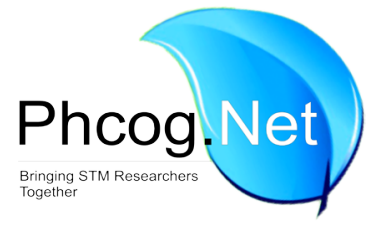

\begin{abstract}
Background: Medicinal plants are the major sources of the crude drugs and natural antioxidants. Berberis species have been used in the treatment of various ailments around the world including Nepal. However, systematic study on phytochemistry and pharmacology of Berberis species from Nepal is lacking. Objectives: To evaluate the antioxidant activity, total phenolic and flavonoid contents of Berberis aristata and Berberis thomsoniana from Sagarmatha National Park. Materials and Methods: Antioxidant activity was measured through 2, 2-Diphenyl-1-Picrylhydrazyl assay. Total phenolic and flavonoid content were estimated using Folin-Ciocalteau and aluminum chloride method respectively. Results: Samples showed dose-dependent radical scavenging activity. Radical scavenging activity of the methanolic extracts of different parts of $B$. aristata and $B$. thomsoniana ranged from 19.38 to $98.47 \%$, with leaf extracts of $B$. thomsoniana showing the strongest activity. The total phenolic content of the samples varied from 11.04 to $65.30 \mathrm{mg} \mathrm{GAE} \mathrm{g}^{-1}$ dry weight whereas total flavonoid content was in between 2.4 to $16.46 \mathrm{mg}$ quercetin/g dry weight. Conclusion: Among the tested samples, leaf extracts of $B$. thomsoniana showed the strongest antioxidant activity and contained the highest amount of total phenolic and flavonoid content. Key words: Berberis, Antioxidant activity, Phenolic content, Flavonoid content, Nepal.
\end{abstract}

\section{INTRODUCTION}

In recent years there have been growing interests among the researchers for the search of new antioxidant molecules with promising activity. Medicinal plants are rich sources of a wide variety of natural antioxidants and exhibit better antioxidant activity than common fruits and vegetables. ${ }^{1-2}$ In recent years, natural antioxidants from medicinal plants have attracted greater interest of researchers and consumers because of their ability to scavenge free radicals ${ }^{3}$ and being safer than synthetic antioxidants. Free radicals are thought to be responsible in the development of a number of disorders, including cancer, neuro degeneration and inflammation. ${ }^{4-6}$

Berberis aristata and Berberis thomsoniana belong to the family Berberidaceae and are known as Chutro in Nepali. There are 27 species of Berberis reported from Nepal. ${ }^{7}$ Berberis aristata is distributed between 1300 $3400 \mathrm{~m}$ and Berberis thomsoniana from 3000-3650 m throughout Nepal Himalaya. ${ }^{8}$ Berberis species are important medicinal plants of Nepal and have been used to cure various ailments in traditional systems of medicine. ${ }^{9-12}$ Berberis aristata is used in skin diseases, diarrhea, dysentery, jaundice, fevers, eye diseases, piles, ulcers, sores and conjunctivitis, stomachache, inflam-

mation, gastric disorders, wound healing, liver and spleen disorders. ${ }^{13-22}$ However, little is known about the traditional use, pharmacology and phytochemistry of Berberis thomsoniana.

Several compounds such as alkaloids, terpenoids, flavonoids, sterols, anthocyanins, lignans, vitamins, proteins, lipids and carotenoids have been isolated, but alkaloids are the main bioactive chemical constituents of Berberis species. ${ }^{23}$ Various pharmacological activities such as antipyretic, antimicrobial, hepatoprotective, wounds healing, antihyperglycemic, antitumor, anticancer, antioxidant and several classes of secondary metabolites (alkaloids, flavonoids, phenolic acids etc.) have been reported from B. aristata. ${ }^{24}$

However, only a few pharmacological studies ${ }^{22,25}$ have been conducted and many works have emphasized on the diversity and traditional uses of Berberis species from different parts of country. ${ }^{13,16,21,26}$ Little information is available on antioxidant activity, total phenolic and flavonoid contents of Berberis species from Nepal. Hence, the present study was conducted to evaluate the antioxidant activity, total phenolic and flavonoid contents of two Nepalese Berberis.
Cite this article: Bhatt LR, Wagle B, Adhikari M, Bhusal S, Giri A, Bhattarai S. Antioxidant Activity, Total Phenolic and Flavonoid Content of Berberis aristata DC. and Berberis thomsoniana C.K Schneid. from Sagarmatha National Park, Nepal. Pharmacog J. 2018;10(6)Suppl:s167-s171. 


\section{MATERIALS AND METHODS}

\section{Collection and identification of plant materials}

Plant specimens were collected from Namche, Thame and adjoining areas of the Sagarmatha National Park in May, 2016. Duplicate specimens were collected for the herbarium preparation. The samples were collected by one of us (LR Bhatt), identified by Dr. Bhaskar Adhikari, Botanist at the Royal Botanical Garden Edinburgh-UK and confirmations were done through the available literature..$^{7-8,26}$ Voucher specimens (B.aristata BRU 036, B. thomsoniana BRU 040) are deposited at Biological Resources unit, Nepal Academy of Science and Technology.

About $500 \mathrm{~g}$ of the healthy plant parts (leaf, stem, bark) of each species were collected. The collected samples were packed in the cotton bags and air dried for several days. The air-dried samples were finely powdered using laboratory blender and kept in zip locked bags until further analysis.

\section{Extraction of the samples}

One gram dried and powdered sample of each plant was extracted in $20 \mathrm{~mL}$ of methanol in shaking incubator $(100 \mathrm{RPM})$ at $37^{\circ} \mathrm{C}$ for $24 \mathrm{~h}$. The obtained solution was filtered and residue extracted again following the same procedure and filtered. Final volume of organic solution was maintained to $40 \mathrm{~mL}$ with the addition of methanol and kept in refrigerator until further analysis.

\section{Antioxidant activity}

Antioxidant activity of samples and ascorbic acid (standard) was estimated using DPPH (2, 2-Diphenyl-1-Picrylhydrazyl) as free radical ${ }^{27}$ with slight modifications. ${ }^{28} \mathrm{DPPH}$ assay is routinely employed for the determination of free radical scavenging activity of plant extracts and is one of the standard and easy colorimetric methods for the evaluation of antioxidant properties of pure compounds. ${ }^{29-30}$ In this test, the antioxidants reduce the DPPH radical to a yellow colored compound and the extent of the reaction depends on the hydrogen donating capacity of the antioxidants. ${ }^{31}$ Different concentrations of sample parts and ascorbic acid were prepared in methanol. Samples and standard solutions were mixed with $0.3 \mathrm{mM}$ DPPH into 96 well plates in 1:1 ratio. The mixture after gentle shaking was incubated at room temperature in dark for about 30 minutes. The absorbance was measured at $517 \mathrm{~nm}$ using Epoch 2 ELISA plate reader and the percentage DPPH radical scavenging activity of the samples was determined using following formula.

$$
\text { DPPH Radical Scavenging Activity }(\%)=\frac{[(\mathrm{Ac}-\mathrm{As}) \times 100]}{\mathrm{Ac}}
$$

Where, $A c$ and As are absorbances of control and sample respectively.

\section{Total phenolic content}

The Folin-Ciocalteu reagent assay was used to determine the Total phenolic content (TPC) with slight modifications. ${ }^{32}$ An aliquot of the samples $(30 \mu \mathrm{L})$ was introduced into 96 well ELISA plate followed by $150 \mu \mathrm{L}$ of ten times diluted Folin-Ciocalteu reagent and $120 \mu \mathrm{L}$ of $7.5 \%$ sodium carbonate. Well plate was incubated for half an hour in dark and absorbance at $765 \mathrm{~nm}$ was recorded in an ELISA plate reader. Gallic acid was used as a standard and the results were expressed in $\mathrm{mg} / \mathrm{g}$ of gallic acid equivalent.

\section{Determination of total flavonoid content}

Total flavonoid content (TFC) of the extracts was determined as described previously. ${ }^{33}$ About $100 \mu \mathrm{L}$ of appropriate concentration of sample was added to 96 well ELISA plates. Then $100 \mu \mathrm{L}$ of $2 \%$ Aluminum chloride solution was added to it and the reaction mixture was incubated at room temperature for about an hour. After incubation, the absorbance of the solution was measured at $450 \mathrm{~nm}$. Quercetin was used to plot calibration curve and TFC of the sample was expressed as mg Quercetin equivalents per gram of extract.

\section{Statistical analysis}

The data were average of triplicate measurements. Microsoft excel was used to compute means, standard deviation and regression.

\section{RESULTS}

In the present study, antioxidant activity of the extracts of various plant parts of Berberis aristata and Berberis thomsoniana was determined using DPPH (2, 2-diphenyl-1-picrylhydrazyl) assay.

Samples exhibited dose-dependent radical scavenging activity (Table 1). Among the samples, leaf extract of $B$. thomsoniana showed the strongest activity at lowest tested concentration. It exhibited more than $98 \%$ radical scavenging activity at the concentration of $0.625 \mathrm{mg} / \mathrm{g}$. However, there was slight decrease in antioxidant activity on increasing the sample concentration. It seems that $0.625 \mathrm{mg} / \mathrm{g}$ would be optimum concentration of the sample for this assay and there might not be enough free radicals to neutralize the higher concentration of sample. It was followed by the stem and bark extracts of B. aristata (Table 1). However, at higher concentration all the samples exhibited similar radical scavenging activity. Ascorbic acid, a natural antioxidant and positive control showed 96\% radical scavenging activity at $100 \mu \mathrm{g} / \mathrm{mL}$ concentration.

All the tested samples contained different amount of phenolics. The total phenolic content varied from 11.04 to $65.30 \mathrm{mg} \mathrm{GAE} \mathrm{g}^{-1}$ dry weight of the sample (Table 2). Leaf extract of $B$. thomsoniana contained the highest phenolic content followed by leaf extract of $B$. aristata. Stem extract of $B$. thomsoniana contained the least amount of total phenolics.

There is large variation in the total flavonoid content of the plant samples, which ranges from 2.4 to $16.46 \mathrm{mg}$ quercetin/g dry weight (Table 2). Among the tested samples, leaf extract of $B$. thomsoniana had the highest amounts of flavonoids. It was followed by leaf extract of $B$. aristata.

\section{DISCUSSION}

Antioxidant activity, total phenolic and flavonoid content of leaf, stem and bark extracts of B. aristata and B. thomsoniana was determined. Considerable amount of variation was observed among the samples regarding antioxidant ability, total phenolic and flavonoid contents. Among the tested samples, leaf extract of $B$. thomsoniana exhibited highest antioxidant activity. However, with increasing concentration, there was decrease in radical scavenging activity (RSA). It is likely that $0.625 \mathrm{mg} / \mathrm{g}$ concentration of the sample is quite enough to quench the available DPPH radicals. Unavailability of DPPH radicals would have contributed in decreasing the RSA of $B$. thomsoniana leaf extract on increasing the sample concentration.

On analyzing the total phenolic and flavonoid content of the samples, leaf extracts of both the plants possessed the higher content of total phenolic and flavonoid whereas the bark extracts of $B$. aristata contained the least amount of phenol. Likewise stem and bark extract of $B$. thomsoniana were the poorest in total flavonoid content. Based on previous research there is variation in amount of phenolic and flavonoid content in different parts of the plant. ${ }^{34-35}$

Strong DPPH radical scavenging activity of Berberis species was reported from the North-West Himalayan Region of India. ${ }^{36-37}$ While comparing different plant parts of Berberis species, higher antioxidant activity and greater amount of phenols and flavonoids in leaves of B. vulgaris and $B$. croatica was reported. ${ }^{38}$ The antioxidant activity varied mostly in relation to the plant parts while statistically no significant differences were found between B. vulgaris and B. croatica. ${ }^{38}$ Similarly, the amount of total phenolics of root extract of Berberis aristata from western Indian 
Bhatt, et al:: Antioxidant activity, total phenolic and flavonoid content of B. aristata and B. thomsoniana

Table 1: Antioxidant activity of B. aristata and B. thomsoniana by DPPH assay

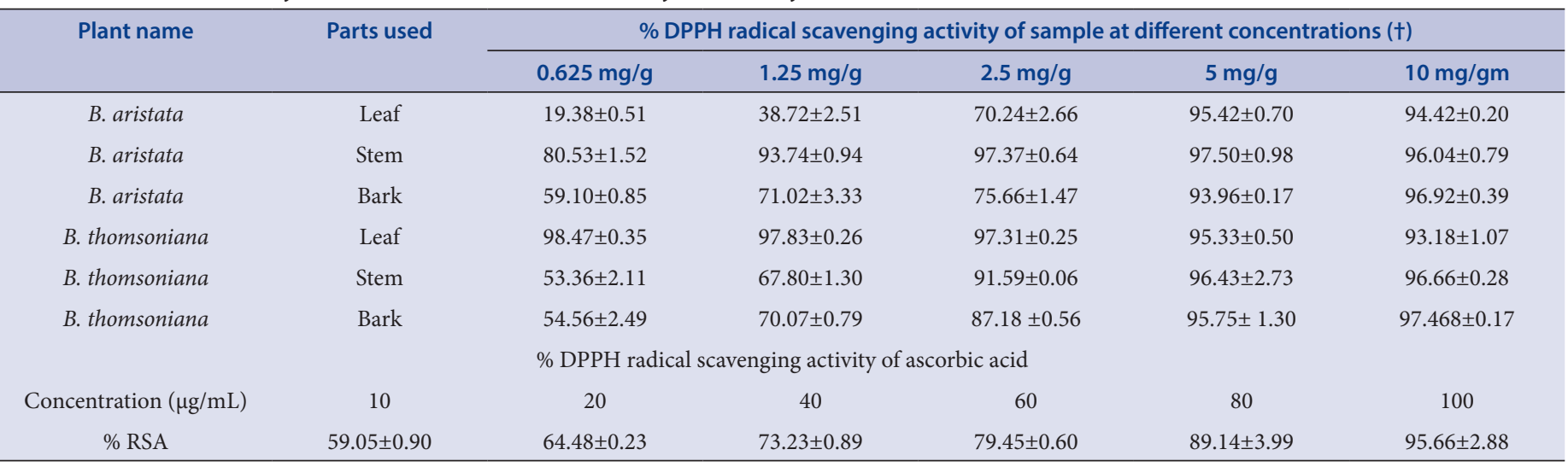

-Values are means of triplicate measurements \pm standard deviation; $\uparrow$ concentration is expressed in $\mathrm{mg} / \mathrm{g}$ dry weight of sample.

Table 2: Total phenolic and flavonoid content in B. aristata and B. thomsoniana.

\begin{tabular}{cccc}
\hline Plant name & Part used & $\begin{array}{c}\text { Total phenolic } \\
\text { content }\end{array}$ & $\begin{array}{c}\text { Total flavonoid } \\
\text { content }\end{array}$ \\
\hline B. aristata & Leaf & $50.44 \pm 8.10$ & $7.82 \pm 0.78$ \\
B. aristata & Stem & $17.70 \pm 2.97$ & $3.03 \pm 0.32$ \\
B. aristata & Bark & $11.04 \pm 2.20$ & $6.08 \pm 0.50$ \\
B. thomsoniana & Leaf & $65.30 \pm 10.72$ & $16.46 \pm 0.30$ \\
B. thomsoniana & Stem & $13.04 \pm 1.86$ & $2.38 \pm 0.03$ \\
B. thomsoniana & Bark & $13.73 \pm 1.65$ & $2.40 \pm 0.10$
\end{tabular}

-Values are expressed as the average of triplicate measurements \pm standard deviation; TPC and TFC is expressed in $\mathrm{mg} / \mathrm{g}$ dry wt. of sample

Himalayas was found quite low and exhibited poor antiradical efficiency. ${ }^{39}$ Stem extract of Berberis lycium Royle showed medium radical scavenging activity and contained moderate amount of total phenols and flavonoids. ${ }^{40}$ Other species of Berberis also possess good amount of phenolics. ${ }^{38,41}$

Among the tested samples leaf extract of $B$. thomsoniana exhibited the highest antioxidant ability and contained higher amount of phenols and flavonoid. It should be further evaluated using multi model antioxidant assays to know its actual antioxidant potential. Similarly, future studies needs to be focused on isolation and purification of active constituents from it.

\section{CONCLUSION}

In the present study extracts from different parts of $B$. aristata and $B$. Thomsoniana showed concentration dependent antioxidant activity. Among the samples, leaf extract of $B$. thomsoniana showed strong antioxidant activity and possess higher amount of total phenols and flavonoids. There is no previous report on the traditional use, phytochemistry and pharmacology of $B$. thomsoniana; further research on this plant should be carried out. The results revealed that extracts of both the plants possess substantial amount of phenols and flavonoids and exhibited strong DPPH radical scavenging activity.

\section{ACKNOWLEDGEMENT}

We are thankful to NAST and our colleagues for various supports during the research periods. Dr. Rosa Ranjit of natural product lab, NAST is thankful for allowing to use ELISA plate reader. Thanks to the $\mathrm{EvK}_{2} \mathrm{CNR}$
Italy for the financial support. We acknowledge the Department of National Park and Wildlife Conservation Nepal for providing the permission for the field work and authority of the Sagarmatha National Park of Nepal for their support.

\section{CONFLICT OF INTEREST}

The authors declare no conflict of interest.

\section{ABBREVIATIONS}

DPPH: 2, 2-Diphenyl-1-Picrylhydrazyl; ELISA: Enzyme-linked immunosorbent assay; TPC: Total phenolic content; TFC:Total flavonoid content.

\section{REFERENCES}

1. Cai YZ, Luo Q, Sun M, Corke H. Antioxidant Activity and Phenolic Compounds of 112 Chinese Medicinal Plants Associated with Anticancer. Life Sci. 2004;74(17):2157-84.

2. Li S, Li SK, Gan RY, Song FL, Kuang L, Li HB. Antioxidant Capacities and Total Phenolic Contents of Infusions from223 Medicinal Plants. Ind Crops Prod. 2013;51:289-98

3. Saeed N, Khan MR, Shabbir M. Antioxidant Activity, Total Phenolic and Total Flavonoid Contents of Whole Plant Extracts Torilis leptophylla L. BMC Complement Altern Med. 2012;12(1):221.

4. Halliwell B. Oxidative Stress and Neurodegeneration: Where Are We Now?. J Neurochem. 2006;97(6):1634-58.

5. Halliwell B. Oxidative Stress and Cancer: Have We Moved Forward?. Biochem J. 2007;401(1):1-11.

6. Ferguson LR. Chronic Inflammation and Mutagenesis. Muta Re Fund Mol. 2010;690(1):3-11.

7. Shrestha KK, Bhattarai S, Bhandari P. Handbook of Flowering Plants of Nepal: Gymnosperms and Angiosperms (Cycadaceae-Betulaceae). Scientific Publishers, Jodhpur, India, (in press). 2018;1:650.

8. Polunin A, Stainton A. Flowers of the Himalaya. Oxford University Press, New Delhi. 1984

9. Joshi AR, Joshi K. Indigenous Knowledge and Uses of Medicinal Plants by Local Communities of the Kali Gandaki Watershed Area, Nepal. J Ethnopharmacol. 2000;73(1-2):175-83.

10. Rokaya MB, Munzbergova Z, Timsina B. Ethnobotanical Study of Medicinal Plants from the Humla District of Western Nepal. J Ethnopharmacol. 2010;130(3):485-504.

11. Joshi K, Joshi R, Joshi AR. Indigenous Knowledge and Uses of Medicinal Plants in Machhegaun, Nepal. Indian J Tradit Knowle. 2011;10(2):281-6.

12. Malla B, Gauchan DP, Chhetri RB. An Ethnobotanical Study of Medicinal Plants Used by Ethnic People in Parbat District of Wester Nepal. J Ethnopharmacol. 2015;165:103-17.

13. Manandhar NP. Plants and People of Nepal. Timber Press, Inc., Portland, Oregon, USA. 2002

14. Bhattarai S. Ethnobotanical Study of Manang District (Central Nepal) and Antibacterial Activities of Some Selected Medicinal Plants. M.Sc. thesis submitted 
to the Central Department of Botany, Tribhuvan University, Kathmandu, Nepal. 2003.

15. IUCN Nepal. National Register of Medicinal and Aromatic Plants. Kathmandu: IUCN Nepal. 2004

16. Bhattarai S, Chaudhary RP, Taylor RSL. Ethnomedicinal Plants Used by the People of Manang District, Central Nepal. J Ethnobiol Ethnomed. 2006;2(1):41.

17. Baral SR, Kurmi PP. A Compendium of Medicinal Plants in Nepal. Mass Printing Press, Kathmandu. 2006.

18. Rajbhandary S, Ranjitkar S. Herbal Drugs and Pharmacognosy: Monographs on Commercially Important Medicinal Plants of Nepal. Ethnobotanical Society of Nepal, Kathmandu. 2006.

19. Annonymous. Medicinal plants of Nepal, Bulletin of the department of medicina plants number 3, Ministry of forest and soil conservation, Department of plant resources, Government of Nepal, Thapathali, Kathmandu; 1997. 2007.

20. Joshi KK, Joshi SD. Genetic Heritage of Medicinal and Aromatic Plants of Nepal Himalayas. Buddha Academic Press. 2007.

21. Bhattarai S, Chaudhary RP, Quave CL, Taylor RSL. The Use of Medicinal Plants in the Trans-Himalayan Arid Zone of Mustang District, Nepal. J Ethnobiol Ethnomed. 2010;6(1):14

22. Bhattarai S. Ethnobotany and Antibacterial activities of selected medicina plants of Nepal Himalaya. PhD thesis submitted to the Institute of Science and Technology, Tribhuvan University, Kirtipur, Kathmandu, Nepal. 2010.

23. Bhardwaj D and Kaushik N. Phytochemical and Pharmacological Studies in Genus Berberis. Phytochem Rev. 2012;11(4):523-42

24. Potdar N, Gelbava T, Nardo LG. Endometrial Injury to Overcome Recurrent Embryo Implantation Failure: A Systematic Review and Meta-Analysis. Reprod Biomed. 2012;25(6):561-71.

25. Bhattarai S, Chaudhary RP, Taylor RSL. Screening of Selected Ethno-medicinal Plants of Manang District, Central Nepal for Antibacterial Activity. Ethnobotany. 2008;20:9-15

26. Adhikari B. Systematics and Phylogeographic Studies of Berberis L. (Berberidaceae) in the Nepal Himalaya. PhD thesis submitted to The University of Edinburgh, Royal Botanic Garden Edinburgh, UK. 2010

27. Blois MS. Antioxidant Determinations by the Use of a Stable Free Radical. Nature. 1958;181(4617):1199-200.

28. Herald TJ, Gadgil P, Tilley M. High-Throughput Micro Plate Assays for Screening Flavonoid Content and DPPH- Scavenging Activity in Sorghum Bran and Flour. J Sci Food Agric. 2012;92(11):2326-31.
29. Mishra K, Ojha H, Chaudhury NK. Estimation of Antiradical Properties of Antioxidants Using DPPH Assay: A Critical Review and Results. Food Chem. 2012;130(4):1036-43.

30. Sanchez MC. Methods Used to Evaluate the Free Radical Scavenging Activity in Foods and Biological Systems. Int J of Food Sci Technol. 2002;8(3):121-37.

31. Bondent $\mathrm{V}$, BrandWW, Bereset C. Kinetic and Mechanism of Antioxidant Activity Using the DPPH Free Radical Methods. Lebens-Wiss Technol. 1997;30(6):609-15.

32. Singleton VL, Rossi JA. Colorimetry of Total Phenolics with PhosphomolybdicPhosphotungstic Acid Reagents. Am J Enol Vitic. 1965;16(3):144-58.

33. Woisky RG, Salatino A. Analysis of Propolis: Some Parameters and Procedures for Chemical Quality Control. J Apic Res. 1998;37(2):95-105.

34. Harris CS, Burt AJ, Saleem A, Le PM, Martineau LC, Haddad PS, et al. A Single HPLC-PAD-APCI/MS Method for the Quantitative Comparison of Phenolic Compounds Found in Leaf, Stem, Root and Fruit Extracts of Vaccinium angustifolium. Phytochem Anal. 2007;18(2):161-9.

35. James O, Nnacheta OP. Comparative Antioxidant Capacity, Memberane Stabilization, Polyphenol Composition and Cytotoxicity of the Leaf and Stem of Cissus multistriata. Afr J Biotechnol. 2008;7(17):3129-33.

36. Singh H, Lily MK, Dangwal K, Evaluation and comparison of polyphenols and bioactivities of wild edible fruits of North-West Himalaya, India, Asian Pac J Trop Dis, 2015;5(11):888-93.

37. Bhatt ID, Rawat S, Badhani A, Rawal RS. Nutraceutical potential of selected wild edible fruits of the Indian Himalayan Region. Food Chem. 2017;215:84-91.

38. Koncic MZ, Kremer D, Karlovic K, Kosalec I. Evaluation of Antioxidant Activities and Phenolic Content of Berberis vulgaris L. and Berberis croatica Horvat. Food Chem Toxicol. 2010;48(8-9):2176-80

39. Guleria S, Tiku AK, Singh G, Koul A, Gupta S, Rana S. In-vitro Antioxidant Activity and Phenolic Content in Methanol Extracts from Medicinal Plants. J Plant Biochem Biotechnol. 2013;22(1):9-15

40. Akhtar N, Haq I, Mirza B. Phytochemical Analysis and Comprehensive Evaluation of Antimicrobial and Antioxidant Properties of 61 Medicinal Plant Species. Arab J Chem. 2015. http://dx.doi.org/10.1016/j.arabjc.2015.01.013.

41. Gundogdu M. Determination of Antioxidant Capacities and Biochemical Compounds of Berberis vulgaris L. fruits. Adv Environ Biol. 2013;7(2):344-8.

\section{GRAPHICAL ABSTRACT}

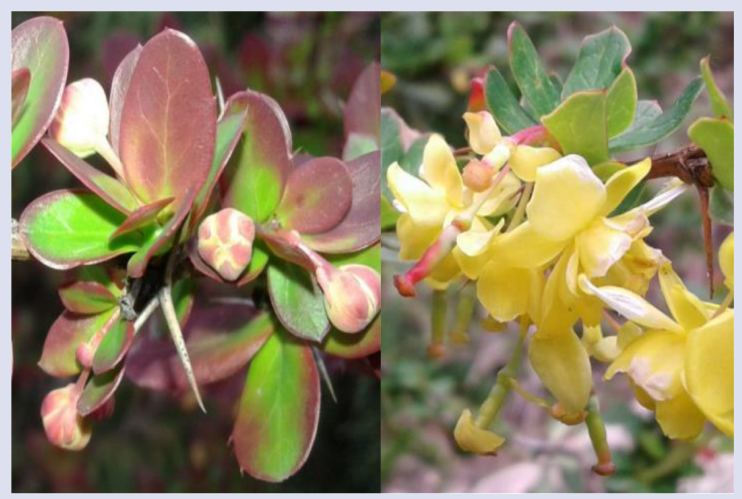

\section{SUMMARY}

- Present study showed that leaf extract of $B$. thomsoniana showed promising antioxidant ability and contained higher amount of phenolics and flavonoids.

\section{ABOUT AUTHORS}

Dr. Lok Ranjan Bhatt is a Senior Scientific Officer at Nepal Academy of Science and Technology (NAST), Khumaltar, Lalitpur, Nepal. He has more than twenty years of experience in the areas of medicinal and aromatic plants, natural products and biomaterials. Currently, he has been working on nutritional composition of wild edible fruits and synthesis and characterization of herbal based polymer micro/nanospheres.

Ms. Bina Wagle is MSc in Botany with specialization in plant pathology from Central Department of Botany, Tribhuvan University, Kirtipur, Nepal. She was a Research Fellow at Nepal Academy of Science and Technology (NAST), Nepal. She is interested in phytochemical analysis of medicinal and aromatic plants.

Ms. Santoshi Bhusal obtained her Masters Degree in Botany from Central Department of Botany, Tribhuvan University, Nepal. She is Assistant Research Fellow at Nepal Academy of Science and Technology (NAST), Khumaltar, Lalitpur, Nepal.

Ms. Minu Adhikari completed her Masters Degree from Central Department of Botany, Tribhuvan University, Nepal and currently she has been working as Assistant Research Fellow at Nepal Academy of Science and Technology (NAST), Khumaltar, Lalitpur, Nepal.

Dr. Shandesh Bhattarai is a Senior Scientific Officer at Nepal Academy of Science and Technology (NAST), Khumaltar, Lalitpur, Nepal. He has been working on ethnobotany, medicinal and aromatic plants and flora of Nepal. 
Dr. Anjana Giri is a Senior Scientific Officer at the Nepal Academy of Science and Technology (NAST), Nepal. She has completed her PhD from University of Natural Resources and Life Sciences, Vienna, Austria. She has been a part of many international and national scientific collaborations, workshops and conferences and has supervised Masters' Students and Research Fellows over the years. With more than 20 years of experience in the field of plant sciences, she has published research articles in various national and international scientific journals.

Cite this article: Bhatt LR, Wagle B, Adhikari M, Bhusal S, Giri A, Bhattarai S. Antioxidant Activity, Total Phenolic and Flavonoid Content of Berberis aristata DC. and Berberis thomsoniana C.K. Schneid. from Sagarmatha National Park, Nepal. Pharmacog J. 2018;10(6) Suppl:s167-s171. 